\title{
Menisküs lezyonlarında görüntüleme
}

\author{
Imaging of meniscal tears
}

\author{
Hamza Özer ${ }^{1}$, Ahmet Yıldırım² \\ ${ }^{1}$ Gazi Üniversitesi Tıp Fakültesi, Ortopedi ve Travmatoloji Anabilim Dalı, Ankara, Türkiye \\ 2Selçuk Üniversitesi Tıp Fakültesi, Ortopedi ve Travmatoloji Anabilim Dalı, Konya, Türkiye
}

\begin{abstract}
Menisküsler, dizin mediyal ve lateralinde yer alan hilâl şekilli yapılar olup, femur kondilleri ile tibia arasında bulunur. Her iki menisküs de "C" şeklinde olup; lateral menisküs, "C" şeklindeki mediyal menisküse göre daha sirküler bir görünüme sahiptir. Lateral menisküsün ön ve arka boynuzları arasındaki mesafe oldukça kısadır; mediyal menisküsün ise ön ve arka boynuzları arasındaki mesafe daha uzundur. Menisküs yırtıklarının görülme oranı 100.000'de 60-70'tir. Tanı koyulan izole yırtıklar, mediyal tarafta, lateralin üç misli daha fazla görülür. Öykü ve klinik muayene, diğer pek çok ortopedik hastalıkta olduğu gibi \%70 civarında tanı koydurabilir. Manyetik rezonans görüntüleme menisküs yırtıklarının tanısında en sık kullanılan yöntemlerden birisi olsa da, direkt grafi, kontrastlı bilgisayarlı tomografi ve artrografi de tanıda kısmen kullanılmaktadır. Yazımızda, menisküs lezyonlarının tanısında kullanılabilecek görüntüleme yöntemleri ve etkinlikleri tartışılacaktır.
\end{abstract}

Anahtar sözcükler: menisküs; manyetik rezonans görüntüleme; menisküs lezyonları; artroskopi; bilgisayarlı tomografi

\section{GiRiş ve ANATOMi}

Illk kez 1897 yılında Sutton tarafindan körelmiş bir yapı olarak tanımlanan menisküs, günümüzde diz ekleminin fonksiyonel çalışabilmesi ve sağlıklı olması için hayati biryapı olarak kabul edilmektedir. ${ }^{[1]}$ Menisküsün birincil fonksiyonu; diz içi uyumu en üst seviyeye taşıyarak, tibiofemoral eklem içinde yük aktarımını, kıkırdak üzerinde en az stresle sağlamaktır. İkincil olarak; diz içi şok emilimi, propriyosepsiyon, lubrikasyon, stabilite ve nütrisyon görevleri de mevcuttur. ${ }^{[2]}$

Karmaşık anatomik ve biyomekanik özellikleri olan menisküs; temas sporları ve diğer sporlar ile uğraşan gençlerde ve diğer günlük aktiviteler sonucu sedanter grupta yaralanmaya meyilli bir doku olarak karşımıza çıkmaktadır. ${ }^{[3]}$
Meniscus is a crescent-shaped structure medially and laterally located between femur condyles, and tibia. Both menisci are "C" shaped; the lateral meniscus has a more circular appearance than the medial meniscus; the distance between the anterior and posterior horns is rather short. The medial meniscus is reverse $U$-shaped, and the distance between the anterior and posterior horns is longer. The incidence of meniscus tears is 60-70 in 100,000. Diagnosed isolated tears are 3 times more likely to be lateral rather than medial. Story and clinical examination can diagnose about $70 \%$ like many other orthopedic diseases. Magnetic resonance imaging is one of the most commonly used methods for diagnosing meniscal tears but radiography, contrast-enhanced computed tomography, and arthrography are also used in the diagnosis. We will discuss imaging methods and activities that can be used to diagnose meniscus lesions.

Key words: meniscus; magnetic resonance imaging; meniscus lesions; arthroscopy; computed tomography

Menisküs kelimesi Latince'ye, Yunan kökenli meniskos kelimesinden gelmiş olup, ayın hilâl şeklini tanımlamaktadır. ${ }^{[4]}$ Menisküs, dizin mediyal ve lateralinde yer alan hilâl şekilli bir yapı olup, femur kondilleri ile tibia arasında bulunur. Konkav femur kondilleri ve düz olan tibia platosu arasında tam bir anatomik uyum oluşturur. Periferik kenarı kalın ve konvekstir; eklem kapsülünün iç kısmına tutunan C-şeklindeki fibröz bir kıkırdaktır. Tibia eklem yüzeyinin derinleşmesini sağlayan menisküsler, tibianın fonksiyonel uzantıları olarak da kabul edilebilir. Üç boyutlu yapısı oldukça kompleks olan menisküs, temel olarak su, kollajen lifler (sıklıkla Tip 1) ve proteoglikanlardan oluşmaktadır. Menisküsler $C$ şeklinde olup ön ve arka boynuzları arasındaki mesafe oldukça kısadır. Lateral menisküs, "C" şeklindeki mediyal menisküse göre daha sirküler bir

- Illetişim adresi: Prof. Dr. Hamza Özer, Gazi Üniversitesi Tıp Fakültesi, Ortopedi ve Travmatoloji Anabilim Dalı, Ankara, Türkiye Tel: 0312 - 2025528 e-posta: hamzabuz@yahoo.com

- Geliș tarihi: 1 Mart $2018 \quad$ Kabul tarihi: 1 Mart 2018 
görünüme sahipken, mediyal menisküsün ön ve arka boynuzları arasındaki mesafe daha uzundur. Yaklaşık $35 \mathrm{~mm}$ çapa sahip olan menisküsün periferik uzunluğu 110 mm'yi bulmaktadır. ${ }^{[5]}$ Menisküslerin üçgen şeklindeki kesiti üç yüzey gösterir. Üst yüzey içbükey olup femoral kondiller ile temas halindedir. Alt yüzey ise düzdür ve tibial platosu ile temas etmektedir.

Menisküsler ekstra-sinoviyal yapılardır ve beslenmeleri özellik gösterir. Doğumda tamamı vaskülarize olan menisküs, yetişkinlerde genel olarak avasküler kabul edilmektedir; periferik sınır, perimeniskal kapiller pleksustan kısmi olarak beslenmektedir. Mediyal ve lateral genikuler arterlerin superior ve inferior dallarınca beslenir. Meniskosinoviyal bileşkeden giren damarlar "perimeniskal kapiller pleksus"u oluşturur. Bu pleksus, menisküsün \%25-33'lük çevresel kısmını besler. Menisküslerin innervasyon özelliklerini araştıran çalışmalar, propriyoseptif reseptörlerin varlığını göstermektedir. ${ }^{[6]}$ Bu nedenle, menisküsler eklemi aşırı zorlanmalardan koruyan bir propriyoseptif duyu organı olarak da görev yapmaktadır. ${ }^{[4]}$

Menisküse femurdan yansıyan ağırlı̆ın dağııımı, ön ve arka boynuzların kemiğe yapışma yerlerinden tibiaya iletilerek sağlanmaktadır. Mediyal menisküs yaklaşık 3,5 cm boyutunda ve C-şeklinde fibröz kıkırdaktır; önde tibia platosuna anterior interkondiller fossa üzerinde, ön çapraz bağ insersiyosunun 6-7 mm ön kısmına; arkada ise arka çapraz bağ ve lateral menisküsün birleşim noktasına yapışır. Ayrıca, posterior oblik bağ ve semimembranozus tendonu ile kurvetli fibröz bağlantısı vardır. Orta $1 / 3$ bölüm ise periferde eklem kapsülüne, femur ve tibia tarafına yapışmıştır. Tibia tarafındaki kapsüler bağlara koronal bağ denilmektedir. Mediyal menisküs, tibia ve eklem kapsülü ile çok sıkı bir bağlantı göstermektedir. Sıkı yapışmadan dolayı mediyal menisküs daha az hareketlidir ve daha sık yaralanır. ${ }^{[4]}$

Lateral menisküs daha dairesel yapıda olup, ön boynuzu, ön çapraz bağın posterolateralinde interkondiller alana yapışır. Arka boynuz ise posterior interkondiller alana, mediyal menisküsün arka boynuzunun yapışma alanının önüne yapışır. Lateral menisküsün arka boynuzundan mediyal femoral kondil ve interkondiller fossaya iki ligamentöz yapı uzanır. Arka çapraz bağın önünde yer alana Ligamentum meniscofemorale anterior (Humphrey lig.), arkasında bulunana ise Ligamentum meniscofemorale posterior (Wrisberg lig.) adı verilmektedir. Lateral menisküsün eklem ilişkisi, posterior boynuzda bulunan ve eklem içi yer alan popliteus tendonu nedeniyle kesintiye uğrar ve dış yan bağ ile de bir bağlantı göstermez. Bu nedenle, lateral menisküs daha hareketlidir ve daha az yaralanır. ${ }^{[4]}$

\section{FONKSIYON}

Menisküsler, dizin fonksiyonunda oldukça önemlidir. Uzun takipler sonrasında, menisektomi yapılan dizlerde artritik değişikliklerin görülmesi kaçınılmazdır. Eksize edilen menisküs oranı ile dizde görülen hasar miktarı doğru orantılı bulunmuştur; eklem yüzlerindeki menisküs uyumunun rotasyon ve fleksiyonda korunması, kıkırdak hasarının azalmasında önemlidir. Menisküsün varlığı, femur ve tibia kıkırdaklarının temas oranını \%50-70 azaltacaktır. Yük dağılımının bozulması, beraberinde tibiada alan başına binen yükü arttıracak ve dejeneratif süreci de beraberinde getirecektir. Beraberindeki \%74'lük su içeriği diz içinde lubrikasyonu sağlarken, özel biçimi de anteriorda yumuşak doku stabilitesini arttırmaktadır. ${ }^{[7-9]}$

\section{MENISKÜS YIRTIKLARI}

Menisküs yırtıkları yapılan çalışmalarda farklı oranlarda belirtilse de, erkeklerde kadınlara oranla daha fazla görülür $(2,5-4: 1)$. Genel popülasyonda görülme oranı 100.000 'de $60-70$ 'tir. ${ }^{[10]} \mathrm{Hem}$ lateral hem de mediyal menisküs yırtıkları sıklıkla arka boynuzları ilgilendirir; ön boynuzlardaki yırtıklar, genellikle arkadaki yırtıkların uzantısı seklindedir. Tanı koyulan izole yırtıklar, mediyal tarafta, lateralin üç misli daha fazla görülürken, akut ön çapraz bağ yırtığı olan hastalarda genellikle lateral menisküs arka boynuzunda uzunlamasına veya oblik yırtıklar saptanır (Şekil 1). Akut menisküs yırtıklarının yaklaşık 1/3'lük bölümü, ön çapraz bağ yırtıklarına eşlik eder. Genellikle ciddi bir rotasyonel travma sonrası meydana gelir; vertikal düzlemdedir; uzunlamasına veya oblik yönde seyreder. Dejeneratif menisküs yırtıkları ise sıklıkla 4. dekad sonrası erkeklerde görülür. Travma öyküsü her zaman bulunmaz, radyal ya da horizontal ve kompleks yırtıklar daha sıktır. Kondral lezyonlar aynı taraf kompartmanda sıklıkla menisküs yırtıklarına eşlik eder; ekstremite aks bozukluğu bulunabilir. ${ }^{[11]}$

\section{TANI}

Öykü ve klinik muayene, diğer pek çok ortopedik hastalıkta da olduğu gibi \%70 civarında tanı koydurabilir. Yaşlı hastalarda en sık rastlanılan bulgu, yükle artan eklem ağrısıdır. Takılma, kilitlenme gibi yakınmalar daha nadirdir ve belirgin bir travma öyküsü yoktur. Dizilim bozukluğu olan hastalarda, deformite tarafındaki femur kondili de genellikle ağrılıdır. Effüzyon ve sinoviyal hipertrofi saptanabilir; patellofemoral artrit bulguları kliniğe eşlik edebilir. Manyetik rezonans (MR) görüntüleme, menisküs yırtıklarının tanısında en sık kullanılan yöntemlerden birisidir. Yurtiçi ve dışında yapılan çeşitli çalışmalarda MR'nin menisküs 


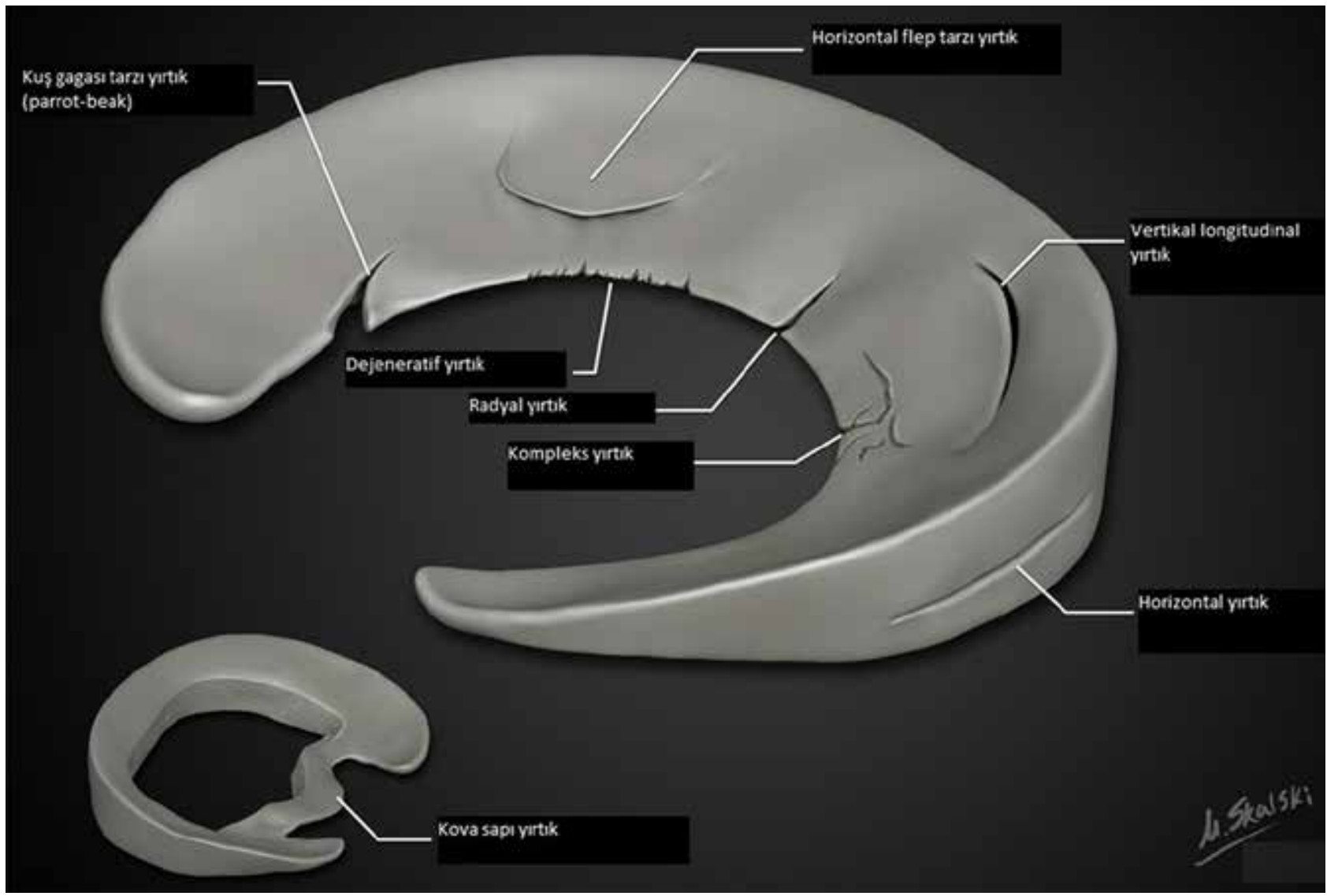

Şekil 1. Sık rastlanılan menisküs yırtıklarının tipleri. (Case courtesy of Dr. Matt Skalski, Radiopaedia.org, rID: 55569)

lezyonlarının tanısındaki doğruluk oranı \%65-99 olarak bildirilmiştir. ${ }^{[11-13]}$

Yazımızda, menisküs lezyonlarının tanısında kullanılabilecek görüntüleme yöntemleri ve etkinlikleri tartışılacaktır.

\section{GÖRÜNTÜLEME YÖNTEMLERi}

\section{Direkt Grafi ve Kontrastlı Bilgisayarlı Tomografi (BT)}

Menisküs lezyonlarının tanısında direkt grafinin etkinliği oldukça düşüktür. Doğrudan menisküs lezyonuna tanı koydurmasa da, menisküs lezyonlarına eşlik edebilecek durumların değerlendirilmesinde önemlidir. Kemik patolojiler ve artropatik değişiklikler ile mediyal eklem aralığı, subkondral kemik kistleri, osteofitler ve sklerozun değerlendirilmesinde etkilidir. Uygun radyografi dozunda, menisküs subluksasyonu, ekstrude menisküs ve kıkırdak kaybı değerlendirilebilir. ${ }^{[11]}$

MR görüntülemenin kısıtlı kaldığı durumlarda kontrastlı çekim yapılan ve dinamik görüntülemenin olduğu floroskopik artrografi ya da kontrastlı BT, valgus ve varus stres dinamik çekimleri ile kullanılabilir. Kök yırtıklarının tanısında MR görüntüleme yetersiz kalırsa yardımcı olabilir. Kontrastlı BT, kıkırdak yaralanmaları ve dejenerasyonların tanısında yardımcıdır. Tekrarlayan yırtıklarda duyarlılığı tama yakın olan kontrastı BT'nin, özgüllügüü \%70 ile \%90 arasında değişmektedir. ${ }^{[11,14]}$

\section{Manyetik Rezonans (MR) Görüntüleme}

MR, menisküs ve ön çapraz bağ lezyonları için günümüzde tedavi öncesi tanıda en uygun görüntüleme seçeneği olarak karşımıza çıkmaktadır. Mediyal ve lateral menisküs görüntülemesinde farklı doğruluk oranları bildirilse de, literatürde MR yardımı ile \%65-99 (geniş serilerde ortalama \%85) doğru tanı konulabileceği bildirilmiştir. ${ }^{[11-13,15]}$ Menisküsün durumu ve yırtığın tipi MR ile kolaylıkla belirlenebilmektedir.

Yüksek çözünürlüklü ve ince kesit kalınlığı olan MR, diz için yapılmış uygun sargı (coil) kullanımı, büyük matriks, küçük FOV (field of view) ile menisküs lezyonlarında tanı doğruluğu artabilir. Literatürde menisküs yırtıklarının değerlendirilmesinde PD (Proton Dansite) 


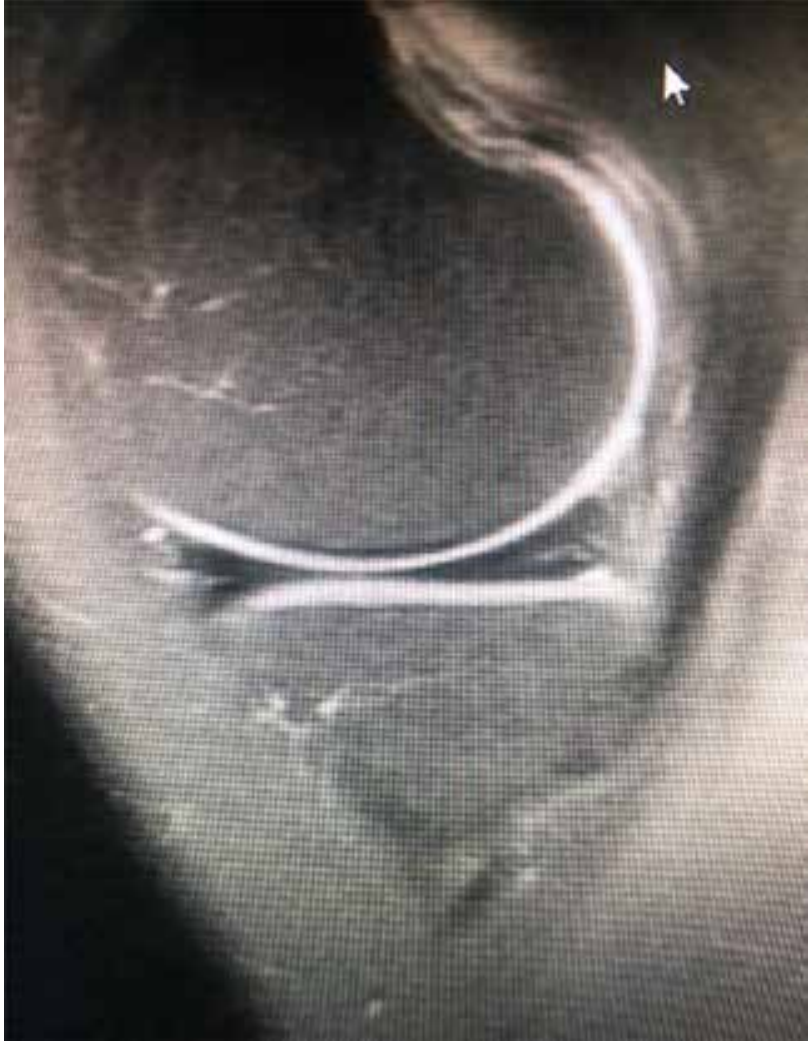

Şekil 2. Mediyal menisküste Evre 1 meniskopati.

sekansının kullanılmasının T2-a'ya göre daha yararlı olacağı belirtilse de, mediyal menisküs kök yırtıklarının değerlendirilmesinde, koronal T2-a görüntülerinin PD'ye göre yüksek doğruluk oranına sahip olduğu belirtilmektedir. Bu nedenle, diz MR'sinde eldeki tüm sekanslar ve görüntüler birlikte değerlendirilmelidir. ${ }^{[16]}$

Koronal ve sagittal düzlemlerde ön ve arka boynuz ile gövdenin kesitlerdeki görünümü üçgen şeklindedir. Sağlıklı menisküs, tüm MR kesitlerinde düşük sinyal yoğunluğundadır. Kanlanmanın normal olduğu ve vasküler yapının bulunduğu çocuk hastalarda, globüler ya da çizgisel yoğunluk artışı fizyolojik olarak görülebilir. Sagittal düzlemde mediyal menisküsün ön boynuzu arka boynuzundan daha dar görünürken, lateral menisküs ön ve arka boynuzu yaklaşık olarak eşit boyutta görülür. ${ }^{[11,17]}$ MR ile yapılacak değerlendirmede; öncelikle menisküs şekil ve boyutlarına bakılmalı, beklenen şekilde bozulma, boyutta azalma olup olmadığı incelenmelidir.

Menisküste görülen sinyal menisküs yüzeyine sadece bir görüntüde ulaşıyorsa; yırtığın artroskopik korelasyonu \%55'in altında iken, koronal ya da sagittal planda iki ya da daha fazla ardışık kesitte yırtık uzanımı

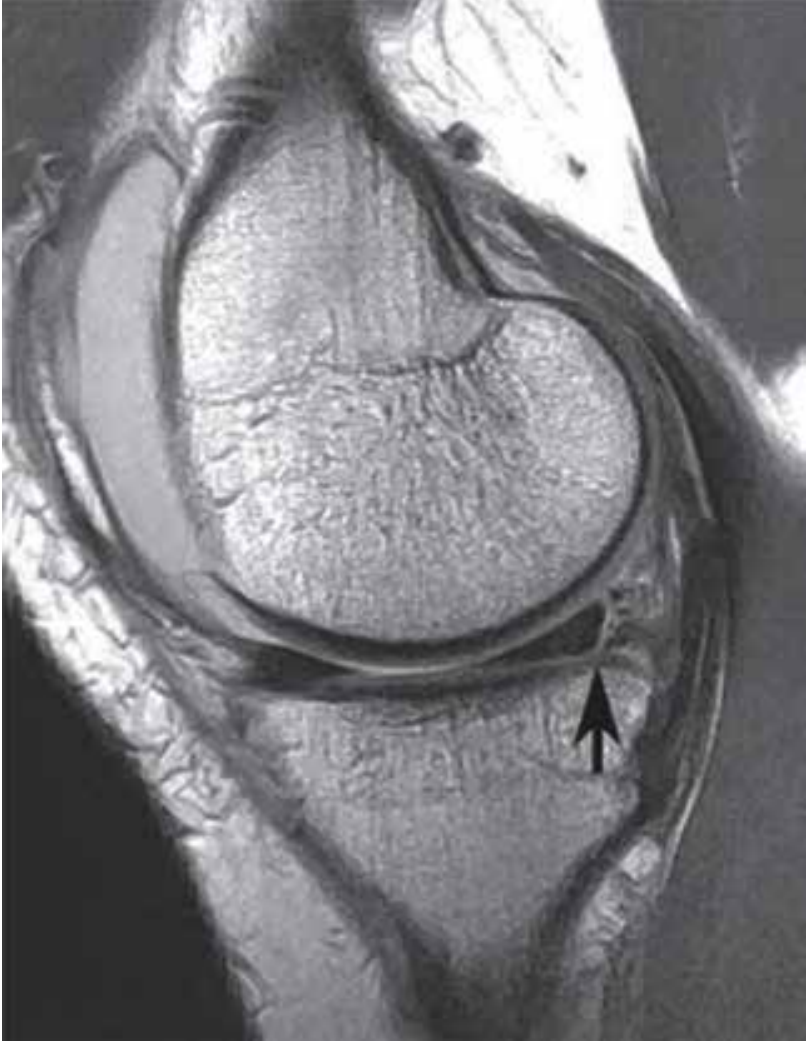

Şekil 3. Mediyal menisküste Evre 2 meniskopati.

mevcutsa; artroskopide yırtık görülme oranı \%90'ının üzerindedir (two-slice-touch rule). ${ }^{[18]}$

Menisküs yırtıkları, sinyal yoğunluk değişikliklerine göre çeşitli derecelerde evrelenebilmektedir. Bu evrelemede; Evre 1 sinyal değişikliği, menisküs içi zorlanan yerlerde mukopolisakkarid vb. birikimine bağlı olarak görülen değişikliktir (Şekil 2). Asemptomatik olarak sporcu ya da diğer bireylerde takip edilebilir. Evre 2 sinyal değişikliği, kapsül periferinden menisküs yüzeyine doğru açılmayan sinyal değişikliğidir ve mediyal menisküs posterior boynuzda sıktır; takip edilebilir (Şekil 3). Evre 3 sinyal değişikliği, artiküler yüze uzanım gösteren sinyaldir, sagittal ve aksiyel görüntülerin birlikte değerlendirilmesi artroskopide görülebilecek yırtık şeklinin ve tamire uygunluğunun anlaşılması için önemlidir (Şekil 4). Evre 3 yırtıklar sadece alt ya da üst yüzeye açılan yırtıkları ifade ederken, Evre 4 (Şekil 5) yırtıklar her iki yüzeye de açılan yırtıkları tanımlamak için kullanılabilir. ${ }^{[17]}$

Sinyal yönü ve lokalizasyonu sayesinde menisküs çevresel yırtıkları artroskopide izlendiği gibi, longitudinal, radyal ya da transvers ve flep ya da oblik yırtıklar olarak sınıflanmaktadır. Saf horizontal yırtıklar, menisküs apeksine uzanır ve eklem yüzeyinde düzensizlik 


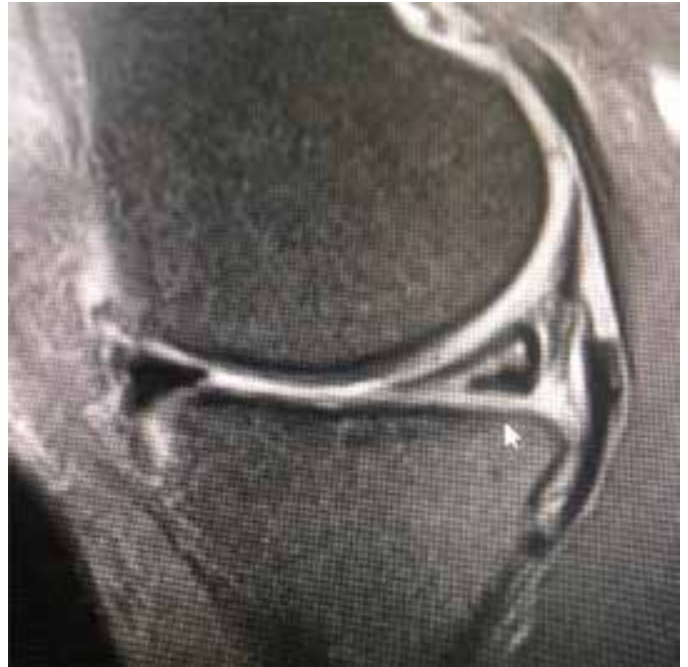

Şekil 4. Mediyal menisküste Evre 3 yırtık.

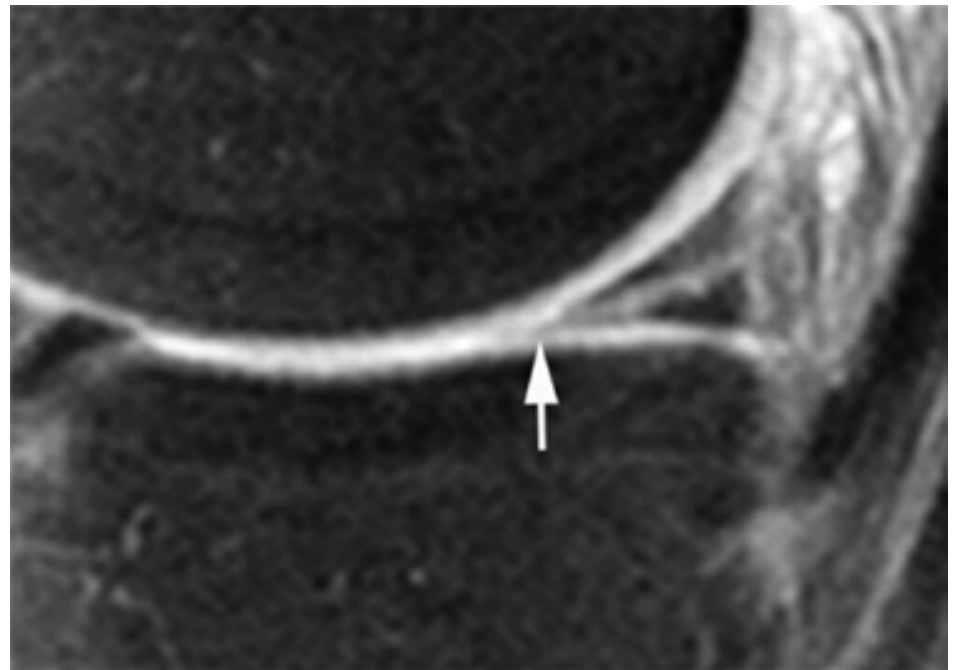

Şekil 5. Mediyal menisküste Evre 4 yırtık.

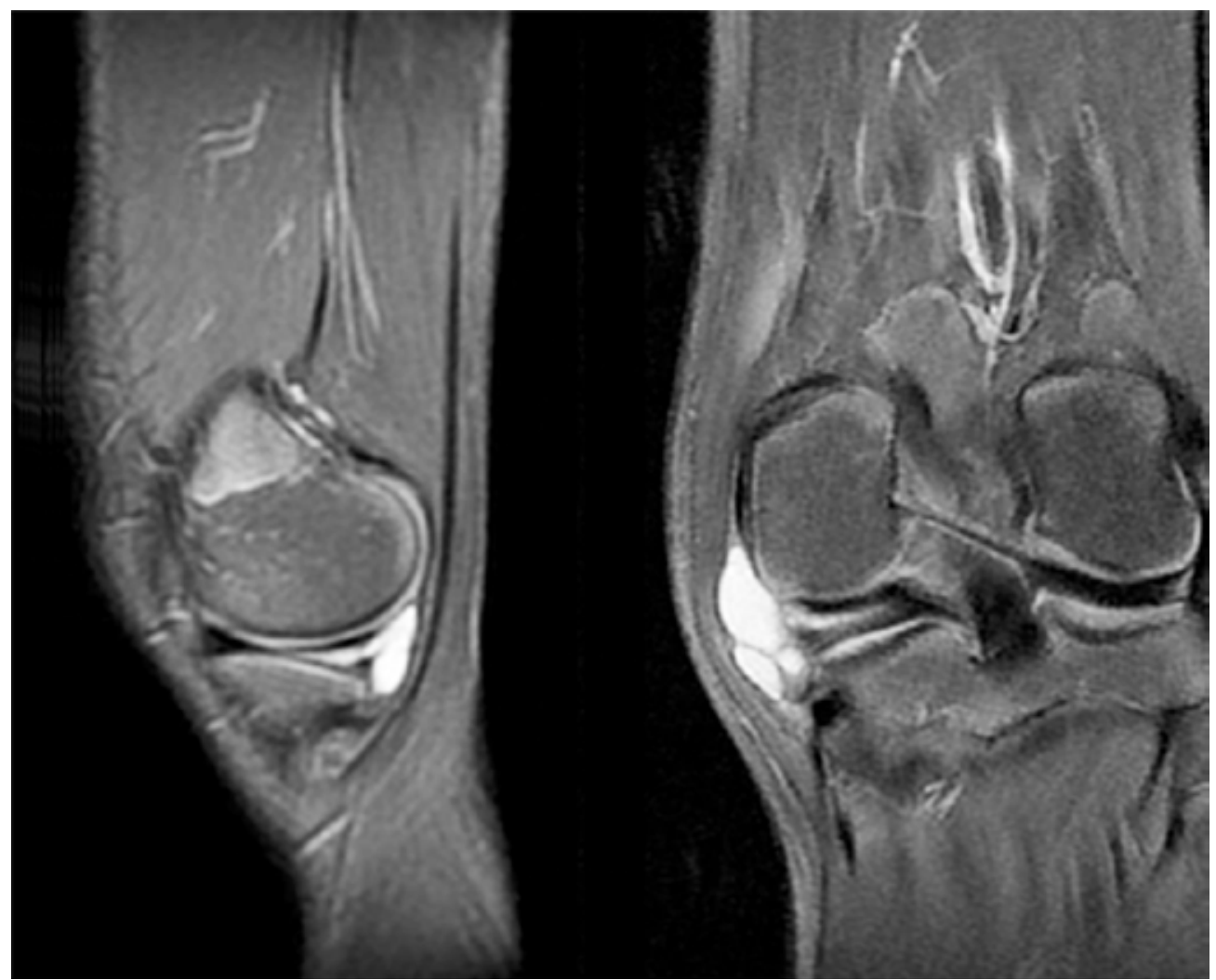

Şekil 6. Mediyal menisküs posteriorunda horizontal yırtık.

oluşturmaz. Vertikal yırtıklar ise üst ve/veya alt eklem yüzeyi ile temas eden longitudinal, radyal ya da oblik yırtıklar olarak uzanır. ${ }^{[19]}$

Horizontal yırtıklar, daha çok 40 yaş üstünde görülen, sıklıkla travma olmaksızın, dejeneratif eklem hastalığı zemininde gelişen ve tibia platosuna paralel uzanarak eklem yüzeylerinden birine ulaşan ya da serbest kenarda sonlanan yırtıklardır (Şekil 6). Parameniskal kistlere, bu yırtık tiplerinde daha sık rastlanır. Superior ya da inferiora uzanan horizontal yırtık yön değiştirirse, flep tarzı yırtık olarak adlandırılır. ${ }^{[19,20]}$ 


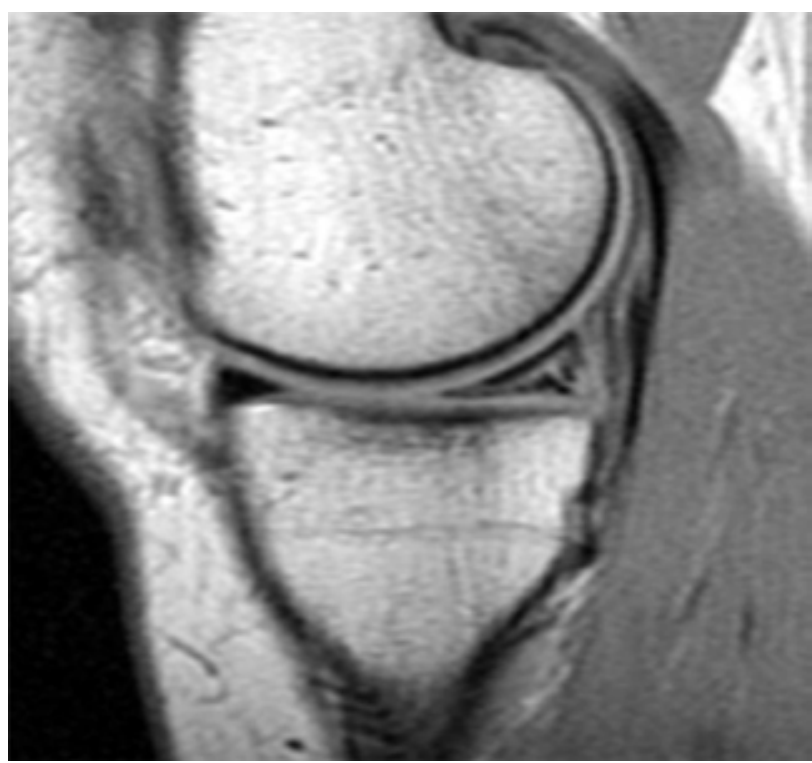

Şekil 7. Mediyal menisküs posteriorunda longitudinal yırtık. (Case courtesy of Radswiki, Radyopaedia.org, rID: 11624)

Longitudinal yırtıklar tibia platosuna dik yerleşerek, menisküsü mediyal ve lateral olarak ayırır. Sıklıkla 40 yaş altında görülür ve travma öyküsü mevcuttur. Ön çapraz bağ yırtıklarına ve iç yan bağ yırtıklarına eşlik etme oranı yüksek olan ve arka boynuzlar ile periferal kesimde olma eğilimindeki yırtıklardır. Görünümü menisküse dik, bir ya da her iki eklem yüzeyiyle de ilişkili çizgi şeklindedir. ${ }^{[18,20]}$ (Şekil 7)

Radyal yırtıklar vertikal yönelimli yırtıklar olup, serbest kenardan menisküse doğru gelişir. Sıklıkla mediyal menisküs arka boynuzu ile lateral menisküsün ön boynuz ve gövde bileşkesini ilgilendirir; menisküs fonksiyonunda dramatik kayıp ile ya da menisküs ekstrüzyonuyla sonuçlanır. Horizontal görüntülerde fark edilmesi daha kolaydır; serbest kenara dik yarıklar şeklinde izlenilebilir. (Şekil 8). Sagittal görüntülerde yerleşim gösteren yırtığın konumuna bağlı olarak "küntleşmiş üçgen”, “yarık”, "yürüyen yarık” ve "hayalet menisküs” gibi işaretlerle tanınır. ${ }^{[20-22]}$

Kök yırtığı, aslında bir çeşit radyal yırtıktır. Meniskal kökler, en iyi koronal sıvı duyarlı sekansta görüntülenebilir. Koronal görüntüde kök, en az bir görüntüde, tibia platosu üzerinde uzanırken görülmelidir (Şekil 9). Sagittal görüntülerde arka çapraz bağın tam mediyalinde, mediyal menisküs arka boynuzu seçilmiyorsa kök yırtığından şüphelenilmelidir. ${ }^{[20]}$ (Şekil 10)

Kova sapı yırtıklar; longitudinal yırtığın içte kalan kesiminin eklem santraline doğru yer değiştirmesiyle gelişir; mediyal menisküste laterale göre daha sık rastlanır.
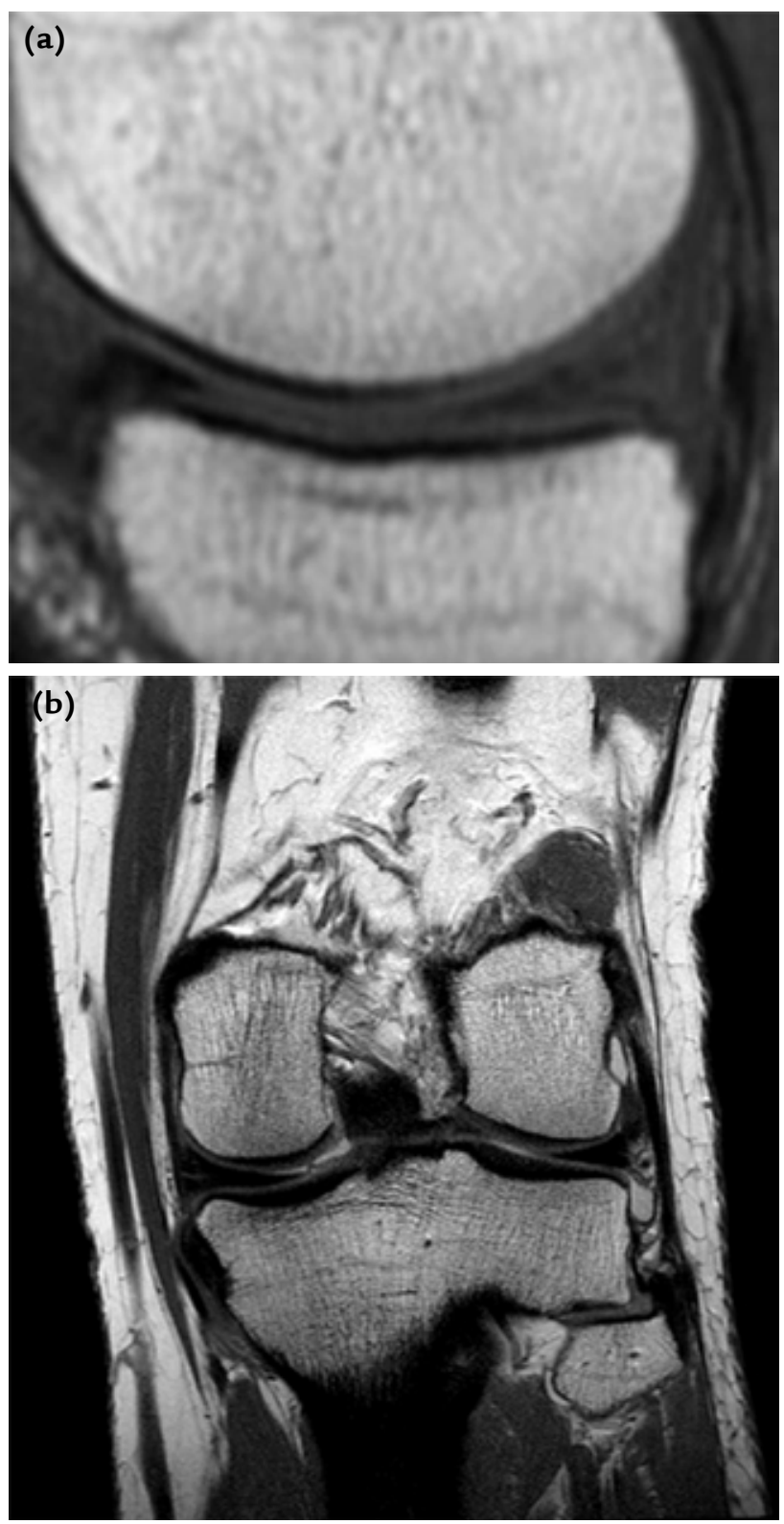

Şekil 8. a, b. Mediyal menisküs posteriorunda radyal yırtık (Case courtesy of Dr. Roberto Schubert, Radiopaedia.org, rID: 14288)

MR görüntülemede farklı bulgular tanımlanmıştır: "görülmeyen papyon, interkondiller çentikte parça, çift arka çapraz bağ ya da çift ön çapraz bağ, çift ön boynuz, orantısız küçük arka boynuz" şeklinde izlenebilir (Şekil 11). ${ }^{111,20,21]}$

Birden fazla menisküs yırtık çeşidinin bileşimi gibi görünen yırtıklar kompleks yırtık olarak isimlendirilir. Menisküs tibia plotosundan $3 \mathrm{~mm}$ üzerinde taşma gösterirse, menisküs ekstrüzyonundan söz edilir (Şekil 12). Tibia platosunun dış kenarı, osteofitler dışlanarak 


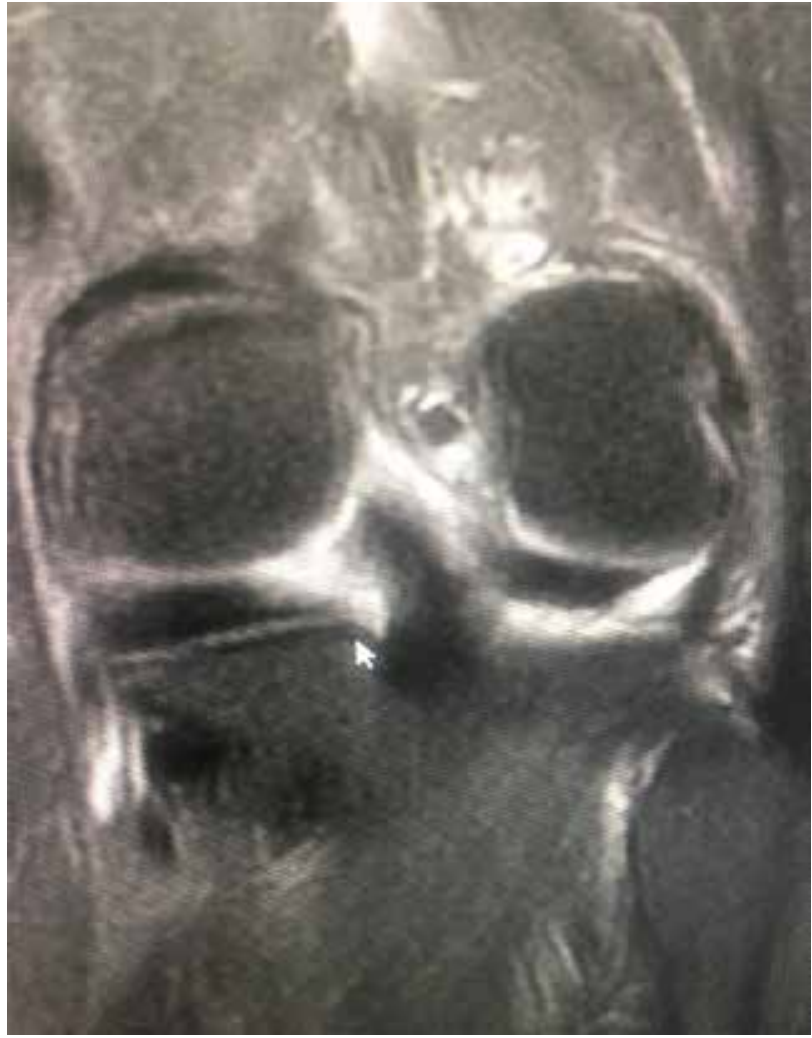

Şekil 9. Mediyal menisküs posteriorunda kök yırtığı.

(Case courtesy of Dr Andrew Dixon, Radiopaedia. org, rID: 44395)

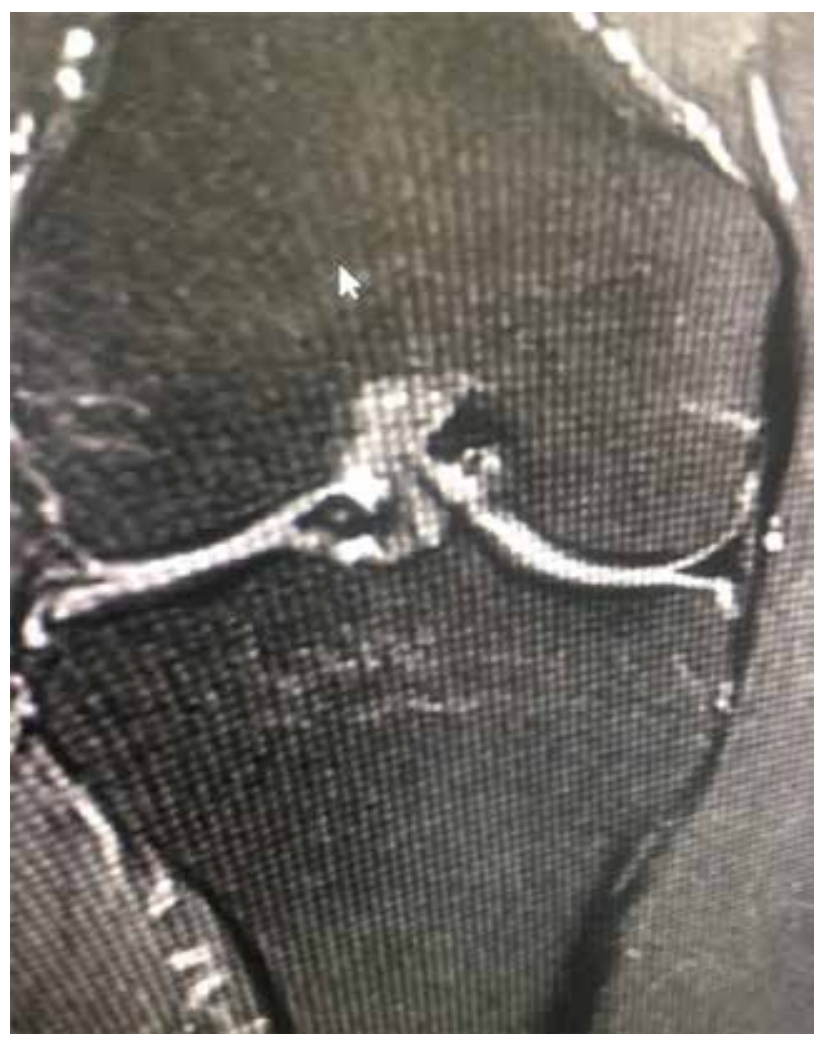

Şekil 11. Lateral menisküste kova sapı yırtık.

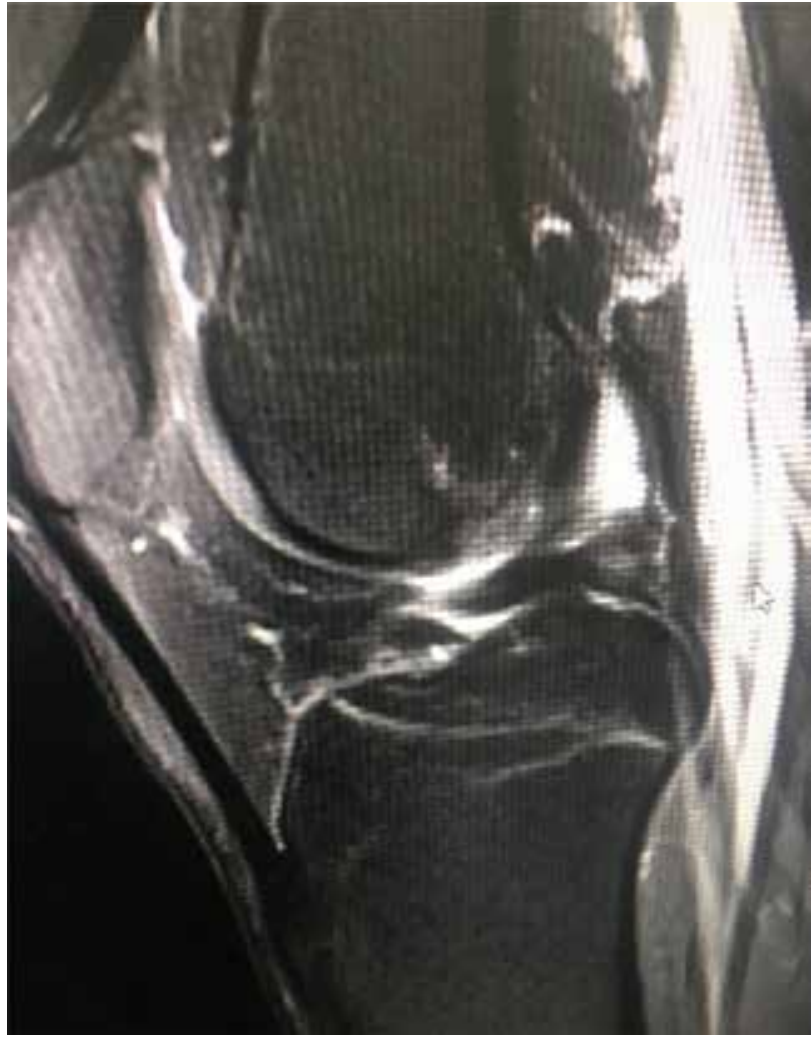

Şekil 10. Lateral menisküste arka kök avulsiyonu.

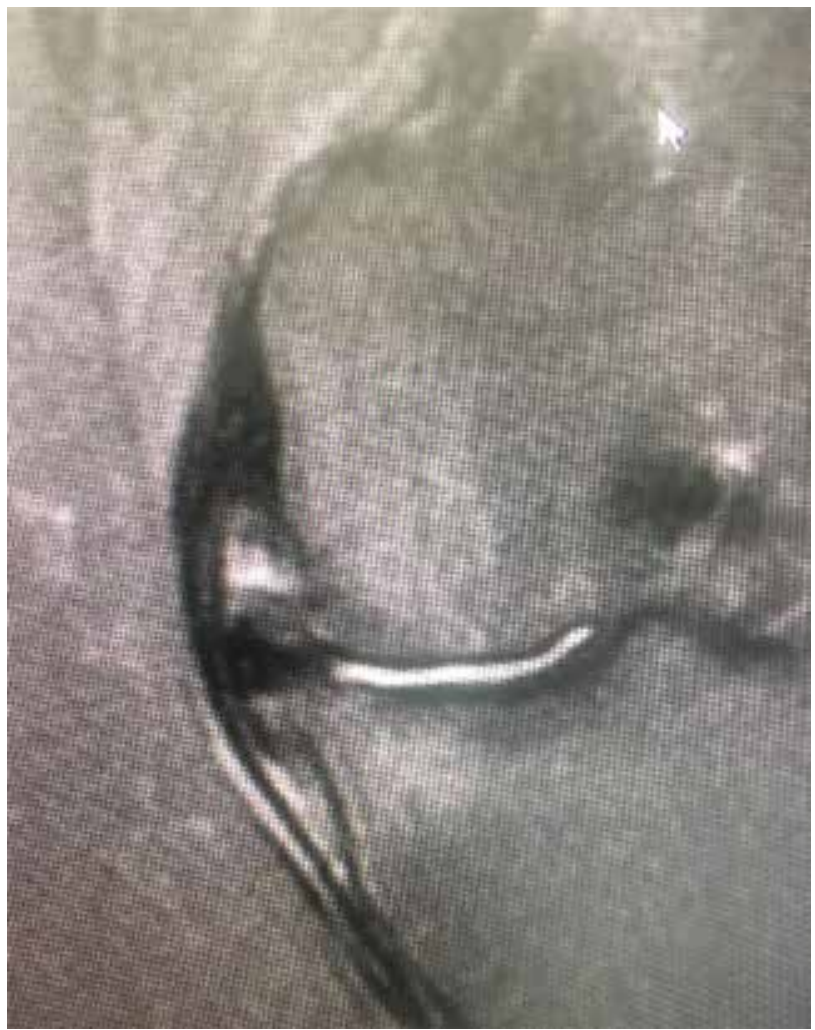

Şekil 12. Mediyal menisküste ekstrüzyon. 


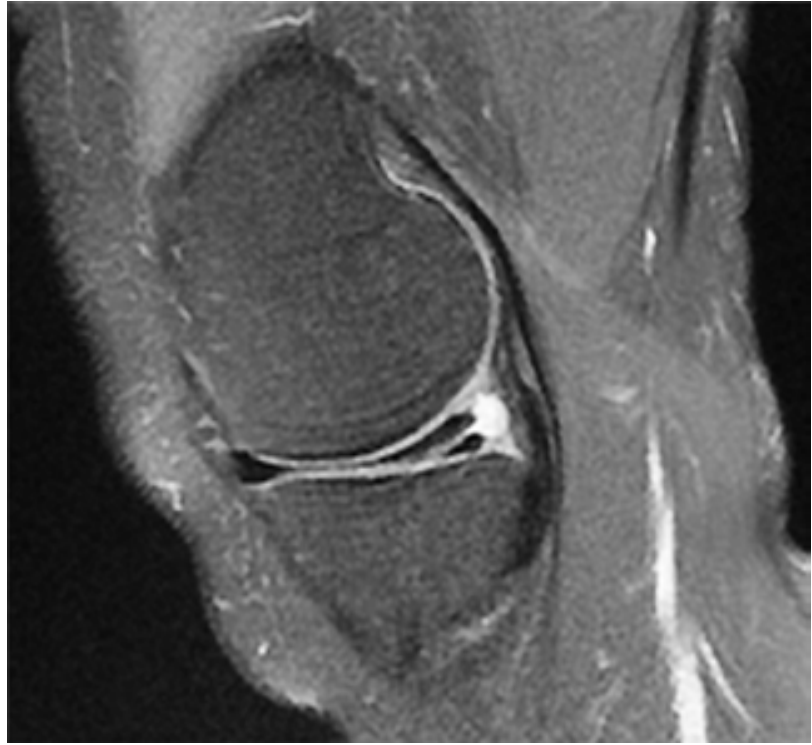

Şekil 13. Meniskal kist.

belirlenmelidir. Ekstrüzyon, diğer yırtık tipleri ve meniskal dejenerasyonla da görülebilmekle birlikte, öncelikle kök yırtığı aranmalıdır. ${ }^{[20]}$

Meniskal kist; intrameniskal, parameniskal ya da sinoviyal kist şeklinde olmak üzere üç tipte izlenebilir. İntrameniskal kist, yırtığın artiküler yüzeye ulaşmadığı durumlarda görülür (Şekil 13). Parameniskal kist yırtığı kateden sıvının hapsolması sonucu gelişir. Yırtıkla devamlılık göstermesi bursa ya da gangliyon kistinden ayırıcı özellikleridir. Sinoviyal kistler, eklem kapsülünün poş oluşturması ile gelişir ve yırtıkla birlikteliği nadirdir.

Cerrahi sonrası menisküs görünümünün doğru değerlendirilebilmesi için, mutlaka cerrahi öncesi görüntülerle korelasyonu gereklidir. Dikkatli bir inceleme ile, kontur düzensizliği, menisküs içine sıvı dolumu ve rezidüel yırtıkta Evre 3 sinyal değişikliği izlenebilir. Menisküs tamiri, Evre 1, 2 ya da 3 sinyal özelliğinde olabilir. Subtotal ve total menisektomide, meniskal bölgede sıvı ya da osteokondral değişiklikler izlenebilir. [11]

Diskoid menisküs gibi meniskal varyantlar da MR ile tespit edilebilir. Diskoid menisküs MR'de çeşitli şekillerde görülebilir. Sıklıkla lateral menisküste diskoid varyanta rastlanabilirken, mediyal menisküste görülme oranı oldukça düşüktür. MR'de koronal görüntüde orta sekansta menisküs gövdesinin $15 \mathrm{~mm}$ ölçülmesi ya da $4 \mathrm{~mm}$ kalınlık ile yapılan sagittal çekimlerde üç ya da daha fazla papyon şeklinin görülmesi, tanıda yardımcıdır. Diskoid menisküs travma sonrası normal menisküse göre daha kolay yırtılabilmektedir. Diskoid menisküste artmış vaskülarite ve disk içi hiperintensite, yırtıkların ayırt edilmesini güçleştirebilir. Ardışık iki görüntüde eklem yüzeyine ulaştığı görülen çizgisel yoğunluk yırtık lehineyken, yaygın yoğunluk artışı hipervaskülariteye bağlı olabilir. ${ }^{[20]}$

\section{KAYNAKLAR}

1. Bland-Sutton J. Ligaments - Their Nature and Morphology. London, UK: H. K. Lewis; 1897.

2. Mow VC, Huiskes R. Basic Orthopaedic Biomechanics \& Mechano-Biology, 3rd ed. Philadelphia: Lippincott Williams \& Wilkins; 2005.

3. Fox AJ, Wanivenhaus F, Burge AJ, Warren RF, Rodeo SA. The human meniscus: a review of anatomy, function, injury, and advances in treatment. Clin Anat 2015;28(2):269-87. Crossref

4. Fox AJ, Bedi A, Rodeo SA. The basic science of human knee menisci: structure, composition, and function. Sports Health 2012;4(4):340-51. Crossref

5. Kohn D, Rudert M, Wirth C, Plitz W, Reiss G, Maschek H. Medial meniscus replacement by a fat pad autograft. Int Orthop 1997;21(4):232-8. Crossref

6. Gao J, Messner K. Natural healing of anterior and posterior attachments of the rabbit meniscus. Clin Orthop Relat Res 1996;328:276-84. Crossref

7. Bylski-Austrow DI, Ciarelli MJ, Kayner DC, Matthews LS, Goldstein SA. Displacements of the menisci under joint load: an in vitro study in human knees. J Biomech 1994;27(4):42131. Crossref

8. Søballe K, Hansen AJ. Late results after meniscectomy in children. Injury 1987;18(3):182-4. Crossref

9. Fukubayashi $\mathrm{T}$, Kurosawa $\mathrm{H}$. The contact area and pressure distribution pattern of the knee: a study of normal and osteoarthrotic knee joints. Acta Orthop Scand 1980;51(16):871-9. Crossref

10. Nielsen $A B$, Yde J. Epidemiology of acute knee injuries: a prospective hospital investigation. J Trauma 1991;31(12):1644-8. Crossref

11. Maffulli N, Longo UG, Campi S, Denaro V. Meniscal tears. Open Access J Sports Med 2010;1:45-54. Crossref

12. Oei EH, Nikken JJ, Verstijnen AC, Ginai AZ, Myriam Hunink M. MR imaging of the menisci and cruciate ligaments: a systematic review. Radiology 2003;226(3):837-48. Crossref

13. Kocabey Y, Tetik O, Isbell WM, Atay ÖA, Johnson DL. The value of clinical examination versus magnetic resonance imaging in the diagnosis of meniscal tears and anterior cruciate ligament rupture. Arthroscopy 2004;20(7):696-700. Crossref

14. De Filippo M, Bertellini A, Pogliacomi F, Sverzellati N, Corradi D, Garlaschi G, Zompatori M. Multidetector computed tomography arthrography of the knee: diagnostic accuracy and indications. Eur J Radiol 2009;70(2):342-51. Crossref

15. Bridgman S, Richards PJ, Walley G, MacKenzie G, Clement D, McCall I, Griffiths D, Maffulli N. The effect of magnetic resonance imaging scans on knee arthroscopy: randomized controlled trial. Arthroscopy 2007;23(11):1167-73.e1. Crossref

16. Wadhwa V, Cho G, Moore D, Pezeshk P, Coyner K, Chhabra A. T2 black lesions on routine knee MRI. differential considerations. Eur Radiol 2016;26(7):2387-99. Crossref 
17. De Smet AA. How I diagnose meniscal tears on knee MRI. AJR Am J Roentgenol 2012;199(3):481-99. Crossref

18. Nguyen JC, De Smet AA, Graf BK, Rosas HG. MR imagingbased diagnosis and classification of meniscal tears. Radiographics 2014;34(4):981-99. Crossref

19. De Smet AA, Nathan DH, Graf BK, Haaland BA, Fine JP. Clinical and MRI findings associated with false-positive knee MR diagnoses of medial meniscal tears. AJR Am J Roentgenol 2008;191(1):93-9. Crossref
20. Sanal HT. Diz Eklemi: Menisküs ve Bağlar. Trd Sem 2016;4:439-52. https://doi.org/10.5152/trs.2016.418

21. Stäbler A, Glaser C, Reiser M. Musculoskeletal MR: knee. Eur Radiol 2000;10(2):230-41. Crossref

22. Welsch $\mathrm{GH}$, Juras $\mathrm{V}$, Szomolanyi $\mathrm{P}$, Mamisch TC, Baer P, Kronnerwetter C, Blanke M, Fujita $\mathrm{H}$, Trattnig S. Magnetic resonance imaging of the knee at 3 and 7 tesla: a comparison using dedicated multi-channel coils and optimised 2D and 3D protocols. Euro Radiol 2012;22(9):1852-9. Crossref 